\title{
On the prenylation of some indolic and imidazolic bases by oxirane auxiliaries under thermal and microwave conditions
}

\author{
Christopher K. Jankowski ${ }^{\mathrm{a}, *}$, Etienne Dako ${ }^{\mathrm{a}}$, Antoun Bou Laouz ${ }^{\mathrm{a}}$, Marcel Delaforge ${ }^{\mathrm{b}}$, \\ Jocelyn R.J. Paré ${ }^{\mathrm{c}}$ and Jacqueline M.R. Belanger ${ }^{\mathrm{c}}$ \\ ${ }^{a}$ Département de chimie et biochimie, Université de Moncton, Moncton, NB E1A 3E9, Canada \\ ${ }^{\mathrm{b}}$ CEA Saclay, iBiTec-S, URA2096, Gif sur Yvette, F-91191, France \\ ${ }^{\mathrm{c}}$ Environment Canada, Green Technologies Division, 335 River Road, Ottawa, ON K1A OH3, Canada
}

\begin{abstract}
The analogue of isoprene, 2-methyl-2-vinyloxirane, a versatile isoprene auxiliary, was reacted with some indolic and imidazolic bases, to add one or more isoprene unit(s), to these compounds. This prenylation was realised by using thermal and microwave assisted pathways, via the nucleophilic opening of the epoxide ring. The biological importance of the prenylated derivatives resides in their potential application as drugs. The aminoacids and small protein biomarkers are obtained from simple epoxide opening reactions. All new compounds were characterised by high resolution NMR, mass spectroscopy, GC-MS and LC-MS as well.
\end{abstract}

\section{Introduction}

In the natural products field, the isoprene moiety is often added following complex biochemical processes (e.g. in farnesylation or geranylgeranylation via a mevalonate pathway) [1]. Such isoprenylation occurs either in microorganisms, in plants and in mammals leading to a large variety of compounds going from alkaloids to proteins. The biosynthesis via the isoprenoid pathway in plants and in microorganisms is responsible for the synthesis of a very diversified group of compounds that are required for their growth and development. These compounds are known to exert also either toxic (mycotoxins as an example) or therapeutic effects (ergot derivatives). Often, one or more prenylation occur on tryptophan leading to compounds having toxic effects such as brevianamides, roquefortine and fumitremorgin [2]. In a few cases, such prenylation lead to potent therapeutic compounds such as ergotamine or lysergic acid derivatives [3]. Recently, on the basis of knowledge of the tryprostatin derivatives, it has been demonstrated that an isoprenyl derivative of a diketopiperazine cyclo Phe-His called phenylahistin inhibits microtubule formation. This compound family is actually in evaluation for their anti-tumoral activities. In plant specimens, compounds having aromatic isoprenylation on phenolic compounds exert antioxidant activities whereas their nonprenylated compounds have prooxidant actions [4,5]. In mammals, protein prenylation play a role in protein trafficking or signalling [6,7].

\footnotetext{
*Corresponding author: C.K. Jankowski, Département de chimie et biochimie, Université de Moncton, Moncton, NB E1A 3E9, Canada. Tel.: +1 506858 4331; Fax: +1 506858 4541; E-mail: krzysztof.jankowski@umoncton.ca.
} 
Can Isoprenyl compound can be transfered to peptides or proteins [8]? This post-translational modification plays a major role in cell proliferation of both normal and cancerous cells. Examples of proteins that undergo prenylation include the family of the Ras oncogenic proteins which are implied in breast, ovarian or pancreatic tumors [6]. The prenylation occurs in such case on the cystein moiety of protein [7] and such prenylation pathway inhibition seems an interesting target for anti microbial agents [9].

Prenylated compounds can also act on other targets such as antioxidant flavanoids [4]. Numerous studies have been devoted to their potential cytotoxic effects and thus to their use as anti-tumoral drugs. This is the case of the taxoids or phenylahistin which are inhibitor of microtubule assembly [10-12]. The isoprenyl moiety is on an imidazole moiety (phenylahistin) and frequently it is located on a tryptophan moiety (roquefortine, verruculogen or tryprostatins as examples) [2]. Such compounds are prenylated forms of 2,5-diketopiperazine. Unfortunately these prenylated, compounds can also exert toxic effects. As an example, roquefortine is considered to be neurotoxic [13-15] and is a potent inhibitor of hepatic cytochrome P450 [16-19], the inhibitory effect being associated to the dehydroimidazole stereochemistry and not to the isoprenyl function.

This prenylation function is primarily realised by assembling several isoprene units after activation by their addition (head-head, head-tail or tail-tail) or cycloaddition [20].

From the primarily formed polyene chains, the addition of some isoprenic units gives also the opportunity to produce other adducts via cyclisation (e.g cyclisation as in squalene biosynthesis) [21], the creation of longer unsaturated chains or finally in the function of Diels-Alder adducts. In general, prenylation involves the introduction of an isoprene unit into the chemical structure. The prenylation is not limited to the addition of one isoprenic unit according to the biomimetic pathways nor is associated to solids Diels-Alder reactions.

This prenylation can also be realised via the $-1,2$ or $-1,4$ addition to one of the double bonds of isoprene, according to thermal, catalytic or photochemical pathways (Scheme 1(a)). Once isoprenic motif present after the reaction, the primary compounds can be better assimilated in diverse physiologic

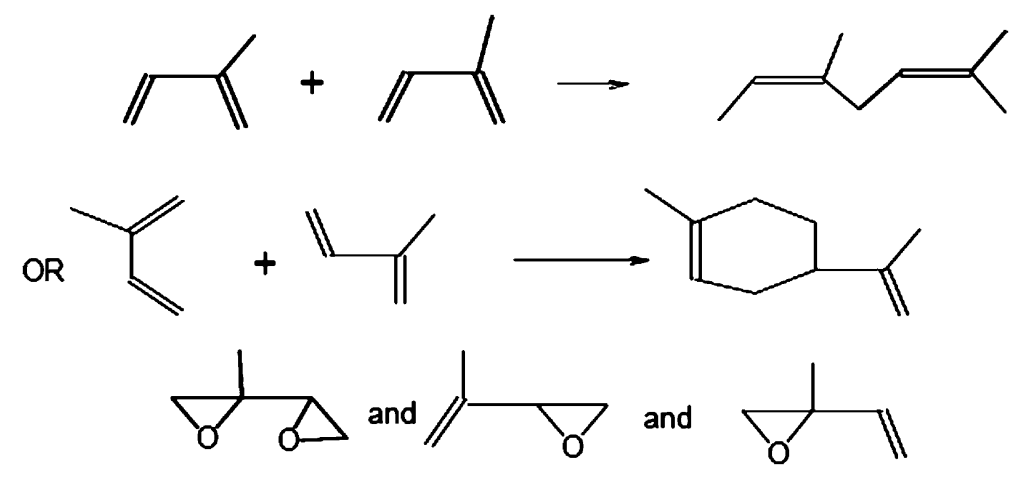

(a)

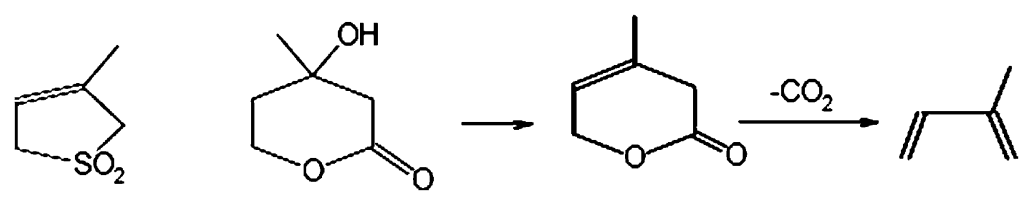

(b)

Scheme 1. Prenylation agents. (a) Isoprene and its auxiliaries; (b) Formation in situ of isoprene: mevalonic acid, isoprene sulfone. 


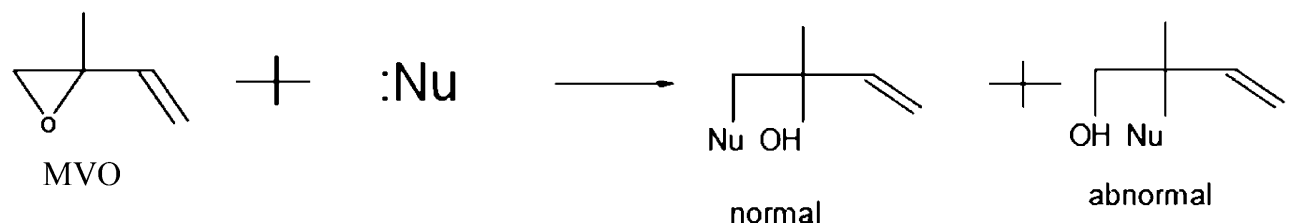

Scheme 2. Opening of 2-methylvinyloxirane (MVO).

processes, e.g. acting as drugs. These structural motifs are interesting toward the design of new drugs or new molecules in biomimetic synthesis. In drug design especially, the prenylation is used to obtain a wide variety of products from proteases inhibitors to antinflammatory compounds, often used as a simple way to introduce linkers [20]. However, in these syntheses the isoprene could be replaced by several auxiliary molecules, more functionalised and offering different selectivity patterns (Scheme 1(b)). In this perspective, the development and the use of isoprene auxiliaries is interesting to prepare new naturals products. Among them, there are three possible epoxides of isoprene (2-methyl-2-vinyloxirane, 3-methyl-2-vinyloxirane, diepoxyisoprene which could also be produced via biosynthesis, e.g. CP 450 oxidation) (Scheme 1(a)) [22], with their stereoisomers, the isoprene sulfone, the mevalonic acid and its lactone (Scheme 1(b)).

The advantage of such auxiliaries is the possibility to react via the epoxide ring opening. For instance, the 2-methyl-2-vinyloxirane (MVO) opening produces the alcohol with the remaining double bond available for further reaction. This nucleophilic opening usually operates as the standard opening (Scheme 2).

The opening of MVO can often be achieved using the amines (N-opening) but also via the extended amino opening through enamine group (C-opening), with the nitrogen assistance situated one $\sigma$ bond further (in $\beta$ position) as the first step. In both cases, the resulting primary opening can be followed with two or more attachments.

The oxirane auxiliaries of isoprene, especially because of their reactivity, combined to their small size and the unhindered access to the epoxide site, can also be attached to the polynucleophilic substrates producing interesting two or more isoprene fixations on the target molecules [23].

In this study, we were interested in using one synthetic analogue of isoprene in particular, the MVO, and react it with some bases present in proteins, in particular those containing indole and imidazole rings. The monoepoxide in particular is expected to be an excellent synthon forming the products issued from specific opening and to the remaining double bond (Scheme 2).

The introduction of the isoprene unit to such naturally occurring bases were the subject of several studies. For example Birch reported on the attachment of the isoprene through biogenetical transfer as in the brevianamides from the diketopiperazine nitrogen atom, either in an indole or indoxyl precursor [24] in the ionic route or in photochemical formation of the brevianamides [25]. Also the epoxide opening with indole derivatives was reported [26] on the hand, the reaction of thio oxirane derivatives with imidazoles produce the normal opening of the epoxide via the C-opening extended amino opening [27], and the substrate 4,5-anhydro-1,2-dideoxypent-1-enitol react with the imidazole to produce the normal opening product via the nitrogen atom $[28,29]$. From these studies one can expect to attach one or more isoprene units to the heterocyclic compounds issued from the biochemical cycles according to the following general Scheme 3 .

The opening of the epoxide can be done the classic way (thermal pathway), or with the utilisation of more recent technology used in organic synthesis, such as the microwave assisted synthesis. 


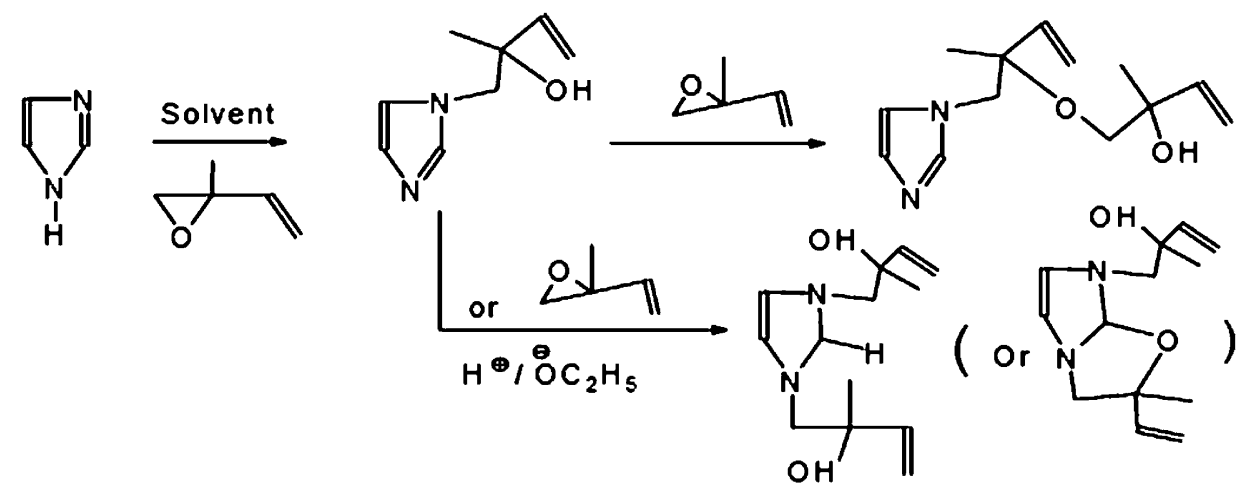

(a)
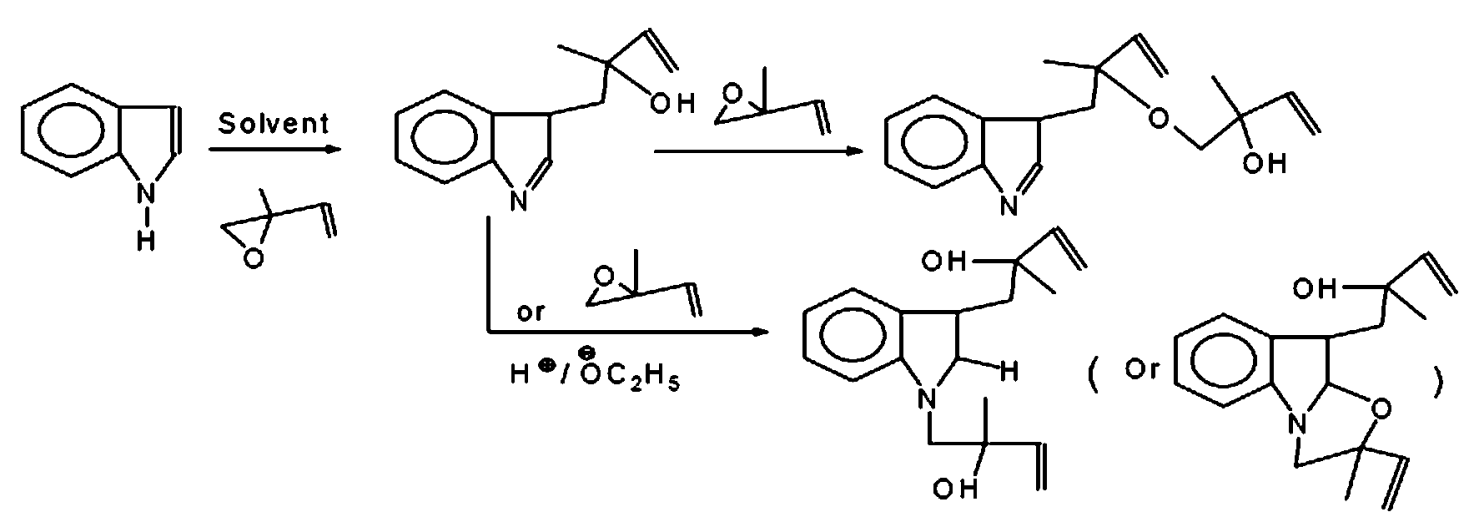

(b)

Scheme 3. Reactions of imidazole and indole substrates. (a) Addition of one or more 2-methyl-2-vinyloxirane (MVO) units to the imidazole substrate; (b) Addition to the indole substrate (normal opening only).

The activation by microwaves, as an energy source of reactions, became popular in organic synthesis following observations by Gedye in 1986 that the microwaves help to realise the reaction in a shorter time and improve their yields [30]. This technology is also interesting because of the recycling of solvents in its typical environmentally friendly approach $[31,32]$. The comparison of the two techniques thermal and microwave assisted enabled to evaluate the efficacy of reactions realised under microwaves pathway especially when compared to the analogue thermal one. In this study we have chosen sixteen compounds from the family of indolic and imidazolic bases (Table 1) as well as some selected model aminoacids and 2,5-diketopiperazines (aminoacid anhydrides).

\section{Experimental}

All products were bought from Aldrich Chemicals (Canada). The NMR spectra were recorded in $\mathrm{CDCl}_{3}$ on a Bruker $200 \mathrm{MHz}$. Chemical shifts were reported in $\delta(\mathrm{ppm})$ with TMS as internal reference. The GC-MS the LC-MS spectra were recorded on a Thermo-Finnigan ion-trap LC Duo, option MSn with an ESI source operated in positive mode, at room temperature, the voltage was maintained at $4.5 \mathrm{kV}$ and a transfer capillary temperature at $250^{\circ} \mathrm{C}$. The collision energy was set at $52 \%$. HPLC separation 
Table 1

Substrates used in this study and their corresponding oxirane adducts

\begin{tabular}{lcc}
\hline Substrats & $(\#)$ & $\begin{array}{c}\text { Molecular weight of expected } \\
\text { one oxirane adduct }\end{array}$ \\
\hline Ajmaline & $(1)$ & $410(17)$ \\
Benzimidazole & $(2)$ & $202(18)$ \\
L-histidine & $(3)$ & $239(19)$ \\
Reserpine & $(4)$ & $692(20)$ \\
L-histidine methylester & $(5)$ & $243(21)$ \\
Tryptophane & $(6)$ & $288(22)$ \\
Tryptamine & $(7)$ & $244(23)$ \\
Harmaline & $(8)$ & $298(24)$ \\
Ibogaine & $(9)$ & $394(25)$ \\
Carboline & $(10)$ & $310(26)$ \\
Cyclo (Phe-Trp) & $(11)$ & 416 \\
Cyclo (Trp-His) & $(12)$ & 407 \\
Cyclo (Phe-His) & $(13)$ & 367 \\
N-acetyl-tryptophane & $(14)$ & 317 \\
Cyclo (Tyr-Pro) & $(15)$ & 344 \\
Roquefortine & $(16)$ & 593 \\
\hline
\end{tabular}

was performs on reverse-phase $\mathrm{C} 18$ Hypersil column $(15 \mathrm{~cm} \times 0.21)$ with debit $200 \mu$, gradient wateracetonitrile $10-80 \%$ and $0.1 \%$ acetic acid.

\subsection{Prenylation by microwaves assisted on the substrates (general method): 24-33}

The microwave instrument used was a STAR-6 from CEM Corp using 6 channels. In (CEM Corp.), each microwaves reactor, a quantity of $10 \mathrm{mg}$ of products (1)-(10) with $50 \mathrm{ml}$ of ethanol and a few drops of oxirane (2-methyl-2-vinyloxirane) were placed. The irradiation time chosen was six minutes under at a power of $180 \mathrm{~W}$ for each microwave. After irradiation, each reactor was removed from the microwave cavity and the ethanol was evaporated using a rotary evaporator and the residue analysed by LC-MS after the removal of the polymer on a Si-gel column. The yields of opening products, varied between 0.3 and $16.6 \%$, are reported in Table 2.

\subsection{Prenylation in thermal pathway (ionic) (general method)}

Ten (10) $\mathrm{mg}$ of substrates 1, 2, 5, 6 and 10 were placed in In one $50 \mathrm{ml}$ round-bottomed flask individually with a few drops of oxirane and ethanol $(5 \mathrm{ml})$ as solvents. The temperature of the reaction was adjusted between 50 and $60^{\circ} \mathrm{C}$, and the time was set a $24 \mathrm{~h}$. The ethanol was then evaporated in vacuum and the mixture was analysed by LC-MS. The yields of products, varied between 0.2 and $18 \%$, were reported in (Table 3).

\section{Results and discussion}

The prenylation by microwave assisted methodology was first tested on some sixteen different compounds in two already mentioned base families, in order to analyse the possibility to attach an isoprenic 
Table 2

Relatives yields of the microwave-assisted prenylation reactions

\begin{tabular}{|c|c|c|c|c|c|c|c|c|c|c|c|c|c|c|c|c|}
\hline Substrats (\#) & 1 & 2 & 3 & 4 & 5 & 6 & 7 & 8 & 9 & 10 & 11 & 12 & 13 & 14 & 15 & 16 \\
\hline $\begin{array}{l}\text { Yield (\%) of starting } \\
\text { compound recovered }\end{array}$ & 18.1 & 13.3 & 7.6 & 15.8 & 4.2 & 2.1 & 10.1 & 32.5 & 60.7 & 71.2 & & & $<5 \%$ & & & $10 \%$ \\
\hline $\begin{array}{l}\text { Efficiencies of opening } \\
\text { product formation }(\%)\end{array}$ & 7.9 & 19.1 & 2.3 & 5.2 & 3.5 & 10.1 & 8.4 & 17.1 & 15.2 & 1.3 & 0.1 & $2-5$ & $2-5$ & $2-5$ & $2-5$ & 2 \\
\hline
\end{tabular}

Table 3

Relatives yields of the prenylation by thermal ionic pathway of the selected compounds

\begin{tabular}{lccccc}
\hline Substrates (\#) & 1 & 2 & 5 & 6 & 10 \\
\hline $\begin{array}{l}\text { Yield (\%) of starting compound } \\
\text { recovered }\end{array}$ & 7 & 4.3 & 20.9 & 2.7 & 6.7 \\
$\begin{array}{l}\text { Efficiencies of opening product } \\
\text { formation }(\%)\end{array}$ & 9.7 & $37.6^{*}$ & 2 & 2.2 & 3.3 \\
\hline
\end{tabular}

${ }^{*}$ This reaction has been tested, for the second time by microwaves assisted with excess of oxirane, and we obtained $40 \%$ of expected product.

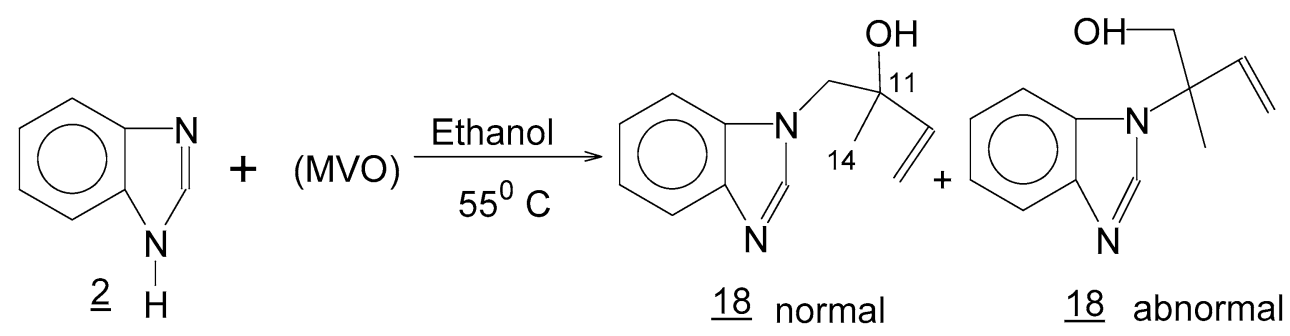

Scheme 4. Formation of product 18.

unit to these structures. We have chosen the products obtained via the microwaves technology with the best yields of and those obtained with minimum of secondary products, to challenge their prenylation by the thermal pathway. The series of substrates (Table 1), when tested in the prenylation by microwaves assisted processes, and analysed by LC-MS, give an approximate yield (efficiencies) of the expected products. These yields are reported in Table 2. We have observed for instance, that five bases: ajmaline (1), benzimidazole (2), L-histidine méthylester (5), tryptophane (6) and carboline (10) substrates are reacting according to our criterion and were then subjected to the thermal prenylation. The results are described in Table 3.

Examples: We have observed that the benzimidazole (2) gives, as far as we know, a new product with the addition of one MVO unit with a considerable yield, this product is 1-(H-benzimidazol-1-yl)2-methylbut-3-en-2-ol (18) (Scheme 4).

The formation of 18 has been realised from 2 and MVO, by prenylation via a thermal pathway (63\% of yield because of the double addition of MVO observed.

The proton and carbon-13 NMR (Bruker $200 \mathrm{MHz}, \mathrm{CDCl}_{3}, \delta \mathrm{ppm}$ ) showed characteristics that confirm the formation of 18 , for example, the methyl group $\mathrm{C} 14$ of 18 at $1.43 \mathrm{ppm}$ correspond to the same shift in $\mathrm{MVO}$, the $\mathrm{CH}_{2}$ group show a single peak at $4.45 \mathrm{ppm}$ confirming the normal opening of epoxide. The double bond of 2 and $18 \mathrm{kept}$ the same chemical shifts corresponding to the starting materials. 


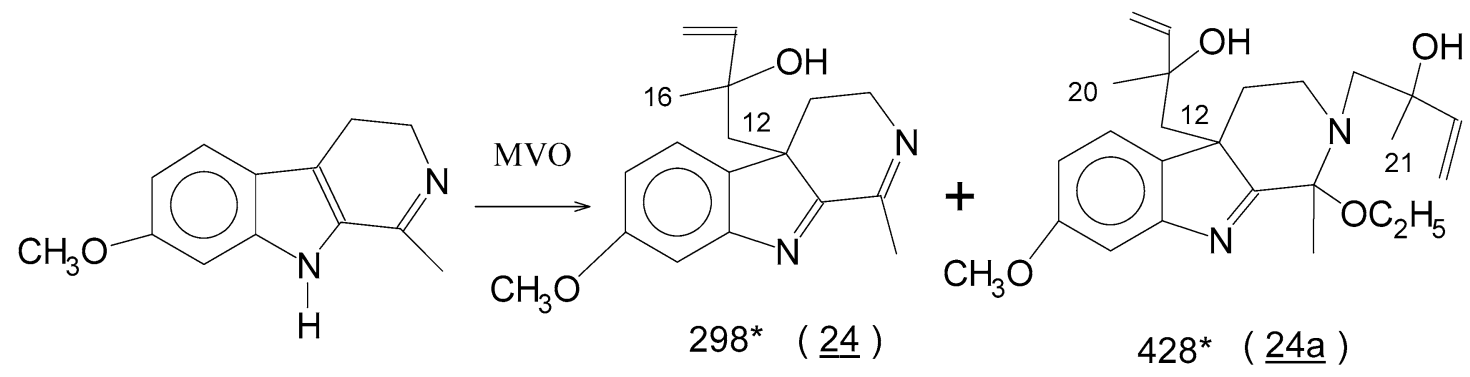

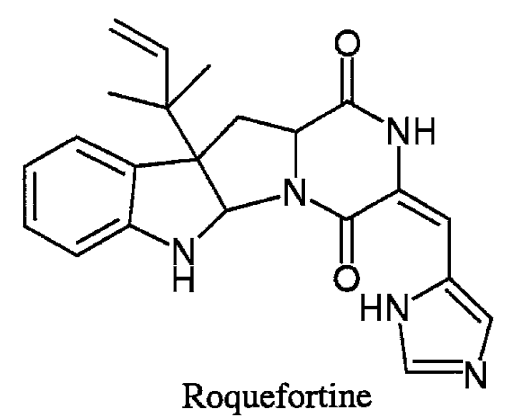

Scheme 5. Formation of 24 and the product with the addition of two oxirane units. Model Roquefortine structure (16). ${ }^{*}$ Masses of the products.

The $\mathrm{C} 13$ showed a chemical shift at $54.3 \mathrm{ppm}$ for the $\mathrm{CH}_{2}$ group $\mathrm{C} 10$ whereas the $\delta$ at $73.5 \mathrm{ppm}$ correspond to the quaternary carbon $\mathrm{C} 11$, compared to 55.3 and $55.2 \mathrm{ppm}$ respectively in the starting substrates. The analysis of GC-MS spectra show $m / z=202,131$ (100\%), 104 and 77 represent respectively to $\mathrm{M}^{+}, \mathrm{M}^{+}-\mathrm{C}_{4} \mathrm{H}_{7} \mathrm{O}, \mathrm{M}^{+}-\mathrm{C}_{4} \mathrm{H}_{8} \mathrm{O}-\mathrm{CHN}$ and $\mathrm{C}_{4} \mathrm{H}_{8} \mathrm{O}-\mathrm{CHN}-\mathrm{CNH}$. Also, we have observed that the harmaline (8) give two or more products with the addition of one or more units of MVO with a considerable yield (Scheme 5).

The formation of 24 has been realised from 8 and MVO, by prenylation via a thermal pathway ( $42 \%$ of yield because of the double addition of MVO). The proton and carbon-13 NMR (Bruker $200 \mathrm{MHz}$, $\mathrm{CDCl} 3, \delta \mathrm{ppm}$ ) showed characteristic chemical shifts confirming the formation of 24 and the product with addition of two oxiranes (24a), for example the methyl group C16 and C20 of both products at 1.52 and $1.73 \mathrm{ppm}$ correspond to the methyl groups of $\mathrm{MVO}$, the $\mathrm{CH}_{2}$ group $\mathrm{C} 12$ of 24 shows a single peak at $1.37 \mathrm{ppm}$ or $\mathrm{CH}_{2}$ methyl group of $24 \mathrm{a}$ at $3.15 \mathrm{ppm}$ according to the normal opening of epoxide. The double bond 8,24 and 24a kept the same chemicals shifts corresponding to the starting materials. The analysis of GC-MS spectra show the presence of at least two products with $24 \mathrm{a}$ as a major one and 24 the minor, corresponding respectively to the $m / z=428,298$. The $m / z=428$ mass is rationalised as the reaction, the solvent (ethanol) provided a radical $\mathrm{OC}_{2} \mathrm{H}_{5}$ to form the 24a. HPLC-MS analysis of this mixture in positive ion (PI/CI) mode, allows the detection of two compounds, at $m / z=297$ (Fig. 1(c)) and 299 (Fig. 1(d)) corresponding to the isoprenylated derivative $(\mathrm{m} / z=299)$ and to its dehydrogenated derivative arising from the reaction of the hydroxy group on a neighbouring substituent. The structure of the product with $m / z=329$ was rationalised accordingly as $\mathrm{M}+\mathrm{C}_{2} \mathrm{H}_{5} \mathrm{OH}-\mathrm{H}_{2} \mathrm{O}$ (Fig. 1(e)). The double adduct is also formed. It is probable that the ethanol adduct is an artefact of the sample preparation (Fig. 1) or the GC-MS analysis. 


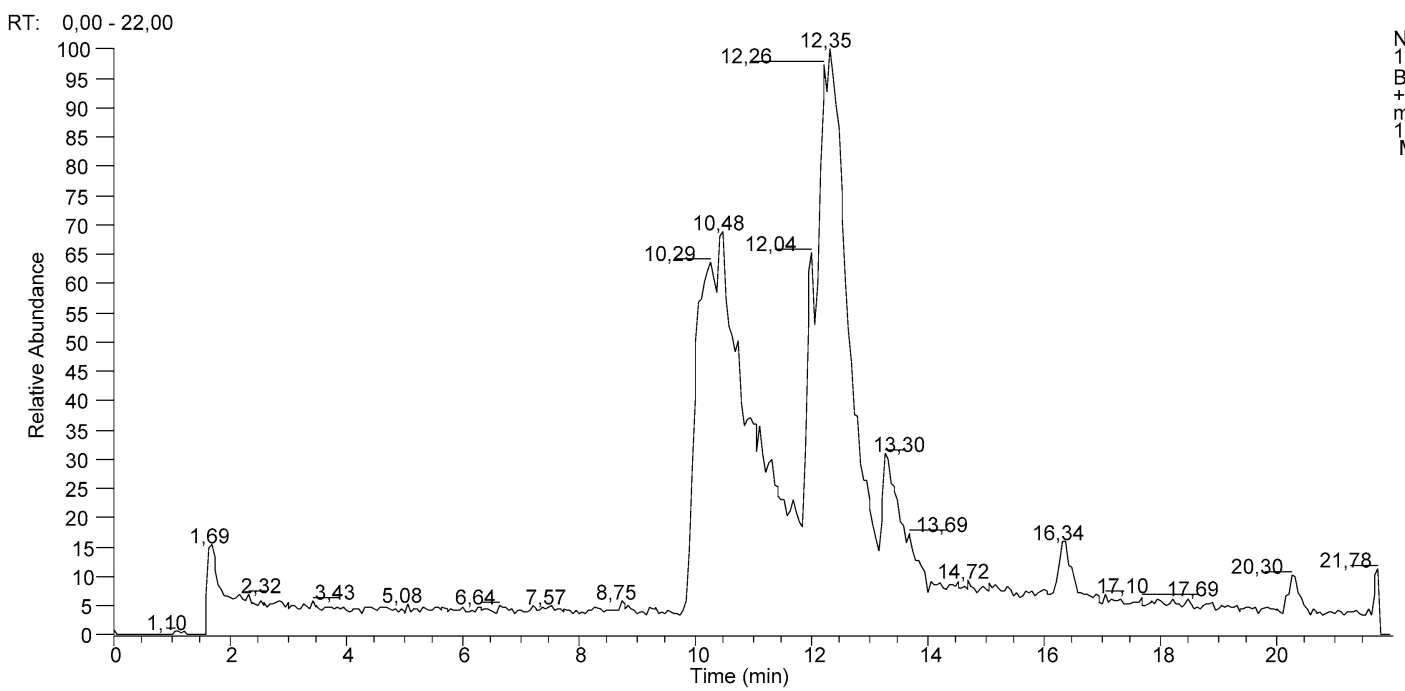

(a)

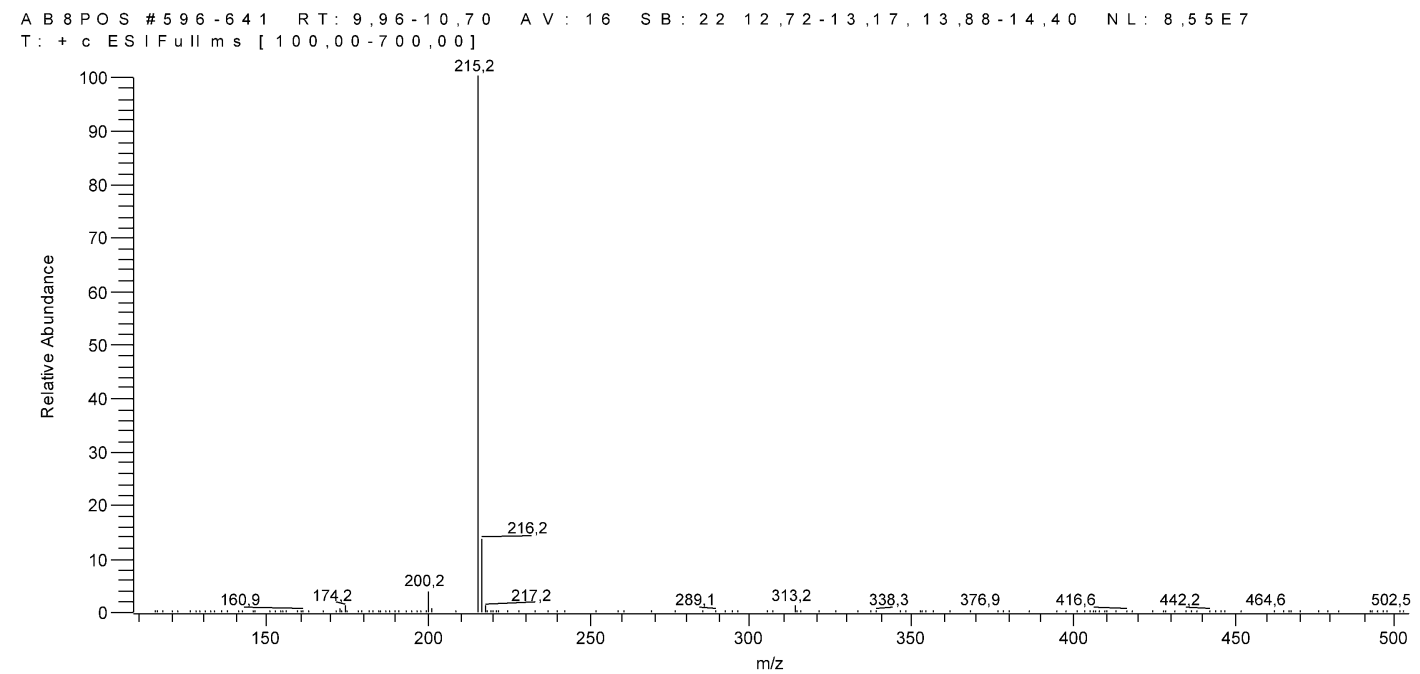

(b)

Fig. 1. Formation of opening product 24 and 24a. (a) LC-MS (MS-2); (b) ion chromatogram of protonated ions $m / z=215$ (starting base).

Finally, six model simple amino acids were reacted with MVO under thermal or microwave assisted conditions. The higher yields of normal opening through the N-terminus for microwave assisted methods were observed. However, the overall yields of the reactions of free amino acids with this isoprene auxiliary remained low (Table 4).

\section{Conclusion}

In this study we have noticed the difference between the prenylation by microwaves assisted and thermal pathway. In general the first pathway gave an inferior yield compared with the thermal one 


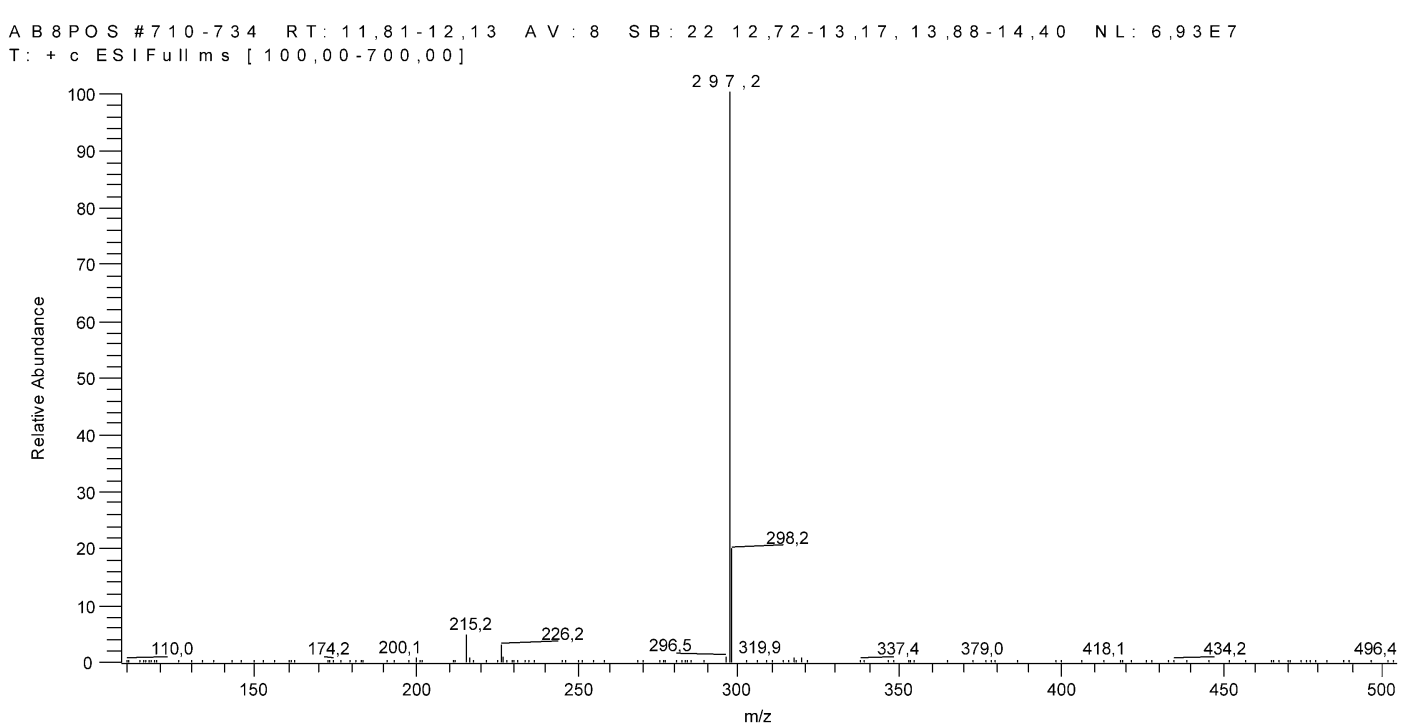

(c)

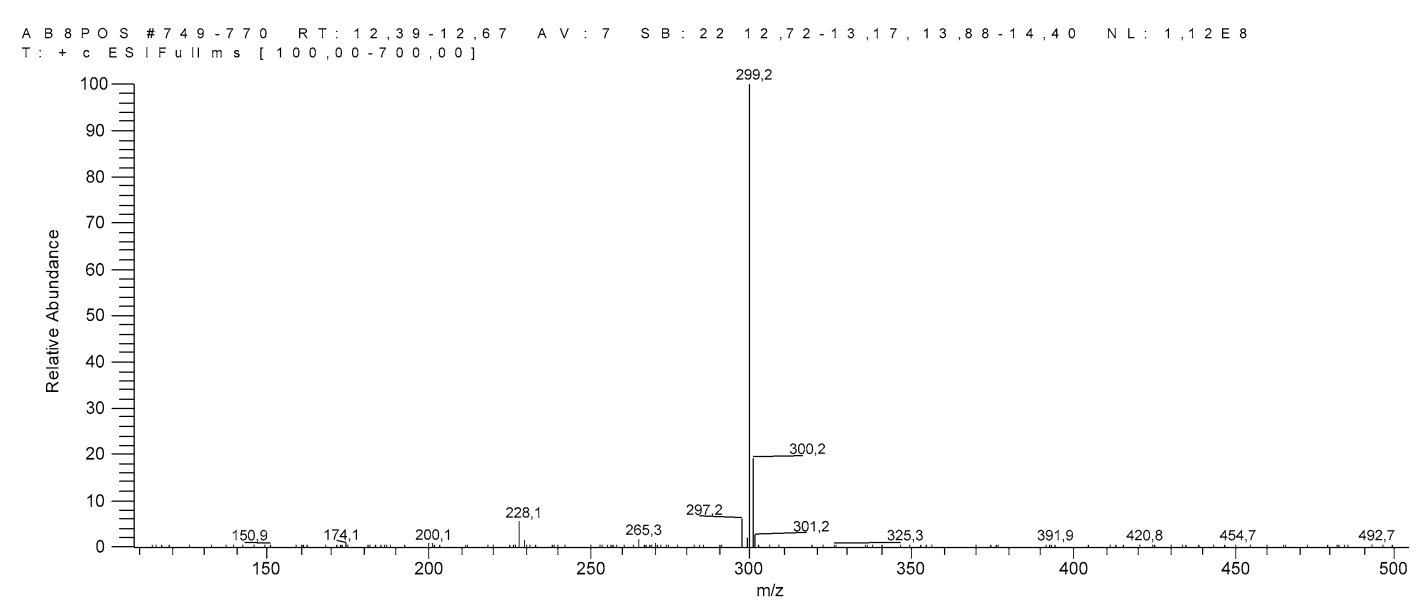

(d)

Fig. 1. (Continued). (c) Ion chromatogram of protonated ions $m / z=297$; (d) ion chromatogram of protonated ions $m / z=299$.

despite the short time of reaction. We also observed that the risk of producing secondary products is higher with the microwaves, all this confirmed with the help of GC-MS and HPLC-MS analysis.

Interestingly, such prenylation leaves an hydroxy group which can be involved in further opening reaction, either extra or intramolecular. Such intra reaction has already been postulated for the formation of lysergic acid derivatives [2]. The prenylation with the MVO is also interesting because of the formation of opening product which can form double bond on the isoprene residue by dehydratation. This double bond can be involved in many bio-organic reactions.

In general, the opening product yields observed under the microwave assist conditions are higher, the striking exception is however the benzimidazole case where the double opening with MVO under thermal conditions is clearly observed whereas under microwave assisted conditions several secondary products were formed. 


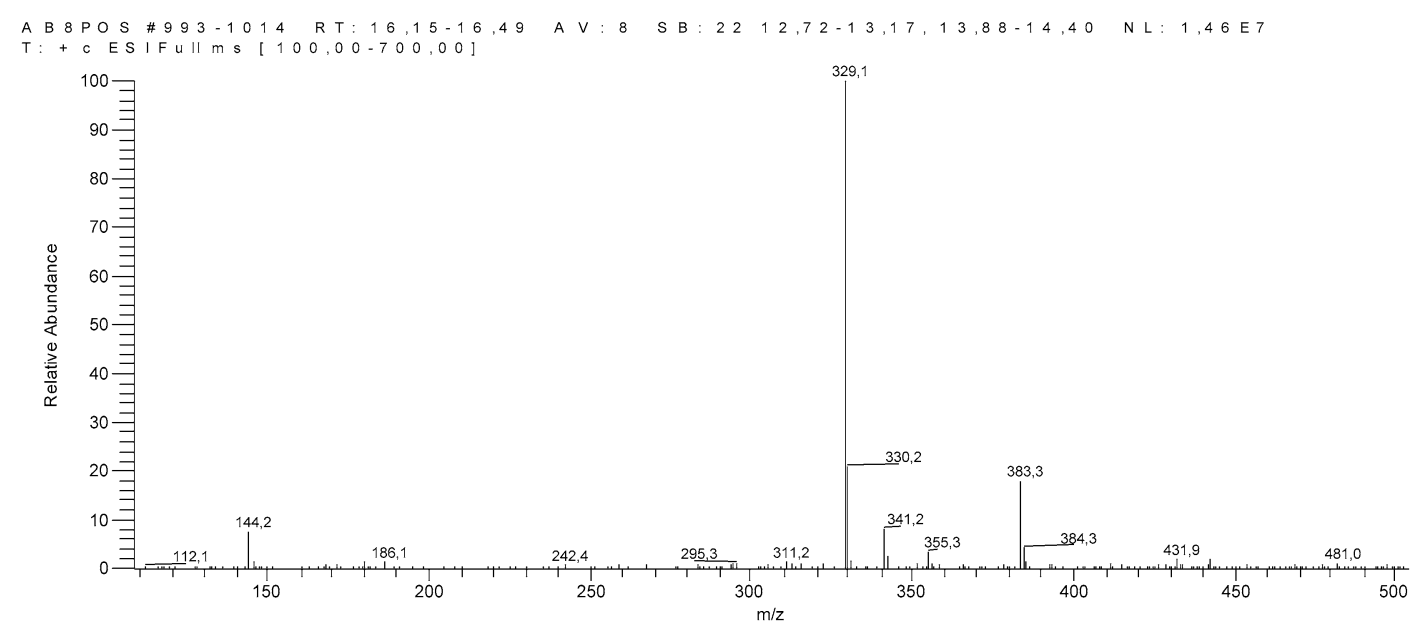

(e)

Fig. 1. (Continued). (e) Ion chromatogram of protonated aggregate ions $m / z=329\left(298+\mathrm{C}_{2} \mathrm{H}_{5} \mathrm{OH}-\mathrm{H}_{2} \mathrm{O}\right)$.

Table 4

Prenylation of amino acids with MVO under microwave assisted and thermal conditions*

\begin{tabular}{lccc}
\hline Amino acids & $\begin{array}{c}\text { Opening product thermal (\%) } \\
\text { chromatogram }\end{array}$ & MAP & $\begin{array}{c}\text { Normal abnormal opening } \\
\text { product rate (from MS) }\end{array}$ \\
\hline Gly & 15 & 27 & $2=1$ \\
Ala & 12 & 22 & $3=1$ \\
Tyr & 10 & 18 & $5=1$ \\
Cys & 7 & 75 & $2=1$ \\
Arg & 11 & 10 & $2=1$ \\
Ser & 13 & 15 & $2=1$ \\
\hline
\end{tabular}

*Conditions: see Section 2.

${ }^{* *}$ Efficiencies: calculated after recovery of untreated starting material.

In all reactions the structure identification was performed by using polynuclear high resolution NMR combined to GC and LC-MS.

\section{Acknowledgements}

We are indebted to the Nuclear Research Centre of Saclay (France) for use of their research facilities as well as to Dr. D. Lesage, Université de P. et M. Curie (Jussieu) for some MS analysis. This study was generously supported by Environment Canada research grants.

This project was also supported by the Université de Moncton, Faculty of Research and Graduate Studies.

\section{References}

[1] P. Allain, Les Médicaments, 3 ème édition, CdM Editions, Bouchemaine, 2000.

[2] R.M. Williams, E.M. Stocking and J.F. Sanz-Cervera, Top. Curr. Chem. 209 (2000), 97-173. 
[3] C.L. Miranda, J.F. Stevens, V. Ivanov, M. McCall, B. Frei, M.L. Deinzer and D.R. Buhler, J. Agr. Food Chem. 48(9) (2000), 3876-3884.

[4] C.L. Miranda, J.F. Stevens, A. Helmrich, M.C. Henderson, R.J. Rodriguez, Y.H. Yang, M.L. Deinzer, D.W. Barnes and D.R. Buhler, Food Chem. Toxicol. 37(4) (1999), 271-285.

[5] M. Sinensky, Biochim. Biophys. Acta 1529(1-3) (2000), 203-209; Review, idem 1484(2-3) (2000), 93-106.

[6] M.H. Gelb, L. Brunsveld, C.A. Hrycyna, S. Michaelis, F. Tamanc and H. Walmann, Nat. Chem. Biol. 2 (2006), 518-528.

[7] D.M. Leonard, J. Med. Chem. 40(19) (1997), 2971-2990 (Review).

[8] A.A. Scholte, L.M. Eubanks, C.D. Poulter and J.C. Vederas, Bioorg. Med. Chem. 12(4) (2004), 763-770.

[9] K.N. Bhalla, Oncogene 22(56) (2003), 9075-9086 (Review).

[10] H. Kanzaki, S. Yanagisawa, K. Kanoh and T. Nitoda, Jpn. J. Antibiot. 55(12) (2002), 1042-1047.

[11] K. Kanoh, S. Kohno, J. Katada, Y. Hayashi, M. Muramatsu and I. Uno, Biosci. Biotechnol. Biochem. 63 (1999), 11301133.

[12] J. Bunger, G. Westphal, A. Monnich, B. Hinnendahl, E. Hallier and M. Muller, Toxicology 202(3) (2004), 199-211.

[13] T.W. Naude, O.M. O'Brien, T. Rundberget, A.D. McGregor, C. Roux and A.J. Flaoyen, J. S. Afr. Vet. Assoc. 73(4) (2000), 211-215.

[14] D.L. Arnold, P.M. Scott, P.F. McGuire, J. Harwig and E.A. Nera, Fd. Cosmet. Toxicol. 16 (1978), 369-371.

[15] C. Aninat, Y. Hayashi, F. Andre and M. Delaforge, Chem. Res. Toxicol. 14(9) (2001), 1259-1265.

[16] T. Usui, M. Kondoh, C.B. Cui, T. Mayumi and H. Osada, Biochem. J. 333 (1998), 543-548.

[17] A.L. Demain and A. Fang, Adv. Biochem. Eng. Biotechnol. 69 (2000), 1-39.

[18] J.F. Sanz-Cervera, E.M. Stocking, T. Usui, H. Osada and R.M. Williams, Bioorg. Med. Chem. 8(10) (2000), $2407-2415$.

[19] O.H. Soo-Kyung, K.I. Jeong, S.D. Ho, Y. Jaemo, K. Hunseung and H. Kyung-Hwan, J. Plant Physiol. 157 (2000), 535542.

[20] R.B. Woodward, F. Sondheimer, D. Taub, K. Heusler and W.M. Mclamore, J. Am. Chem. Soc. 73 (1951), 3547.

[21] P.G. Gervasi, L. Citti, M. Del Monte, V. Longe and D. Benetti, Mutat. Res. 156 (1985), 77.

[22] J.S. Santos, J.C. Smith, M. Delaforge, H. Virelizier and C.K. Jankowski, Eur. J. Biochem. 251 (1998), 398.

[23] J. Baldas, A.J. Birch and R.A. Russell, J. Chem. Soc. - Perk. Trans. 150 (1974).

[24] A.J. Birch and R.A. Russell, Tetrahedron 28 (1972), 2999.

[25] R.C. Harden, T.J. Hodgkinson, A. Mckillop, W.G. Prowse and M.W.J. Urquhart, Tetrahedron 53 (1997), 21.

[26] D.M. Gill, N.A. Pegg and C.M. Rayner, Tetrahedron 52 (1996), 3609.

[27] D.M. Gill, N.A. Pegg and C.M. Rayner, J. Chem. Soc. - Perk. Trans. 1 (1993), 1371-1372.

[28] V. Jäger, U. Stahl and W. Hümmer, Synthesis 23(9) (1991), 769.

[29] V. Jäger and W. Hümmer, Angewandte Chemie Int. Edn 29 (1990), 1169-1171.

[30] R.N. Gedye, F. Smith, K. Westaway, H. Ali, L. Baldisera, L. Laberge and J. Roussell, Tetrahedron Lett. 27 (1986), 279.

[31] K.R. Seddon, Kinet. Katal. 37 (1996), 743-748.

[32] T. Welton, Chem. Rev. 99 (1999), 2071. 


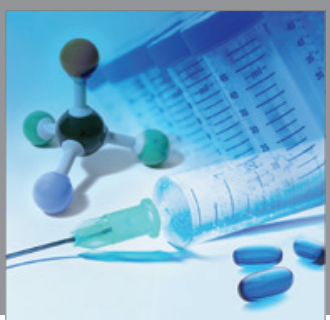

International Journal of

Medicinal Chemistry

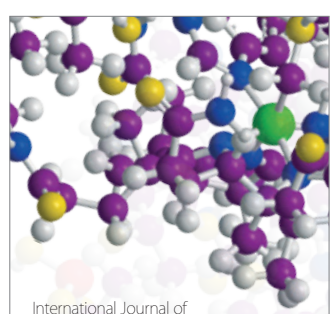

Carbohydrate Chemistry

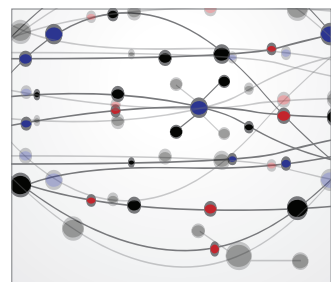

The Scientific World Journal
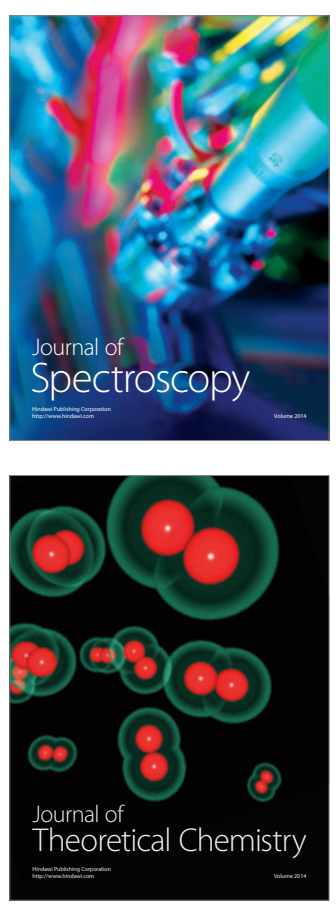
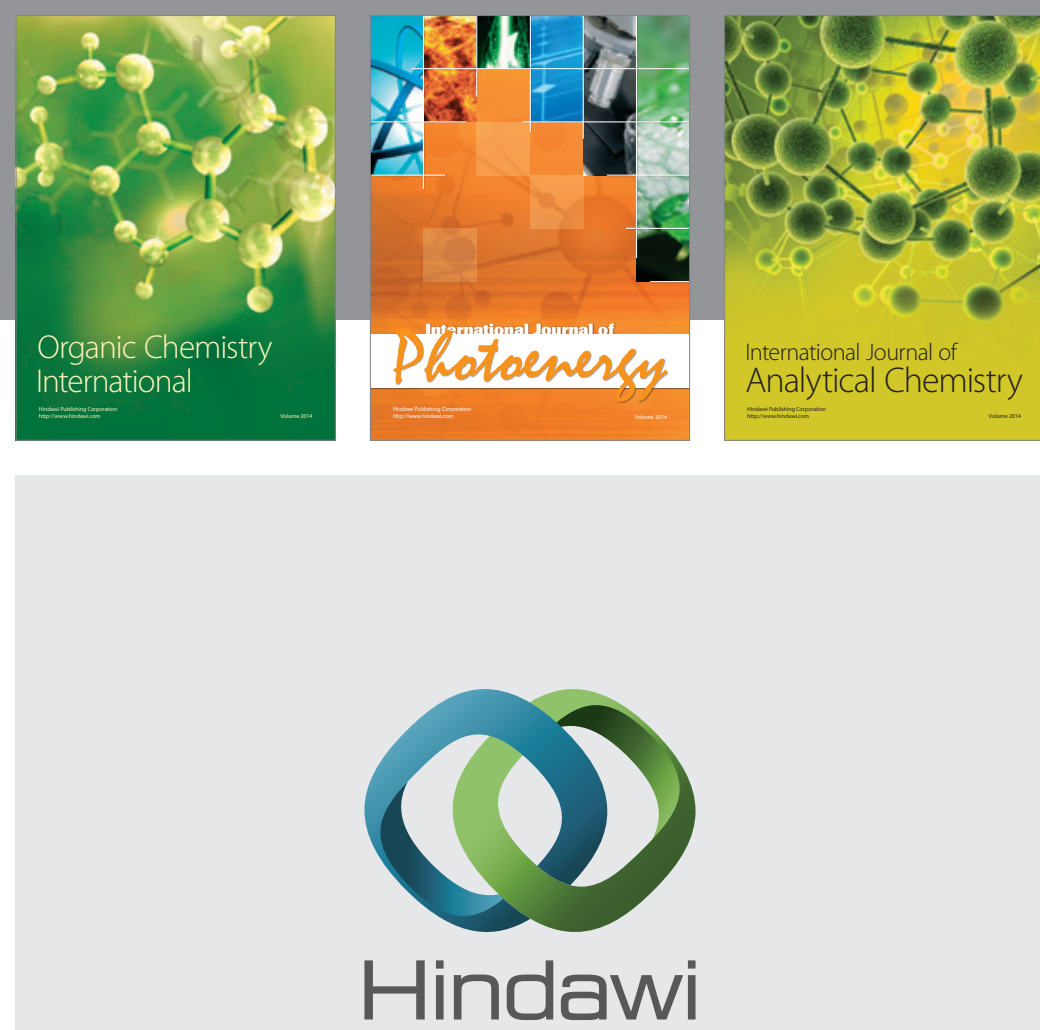

Submit your manuscripts at

http://www.hindawi.com
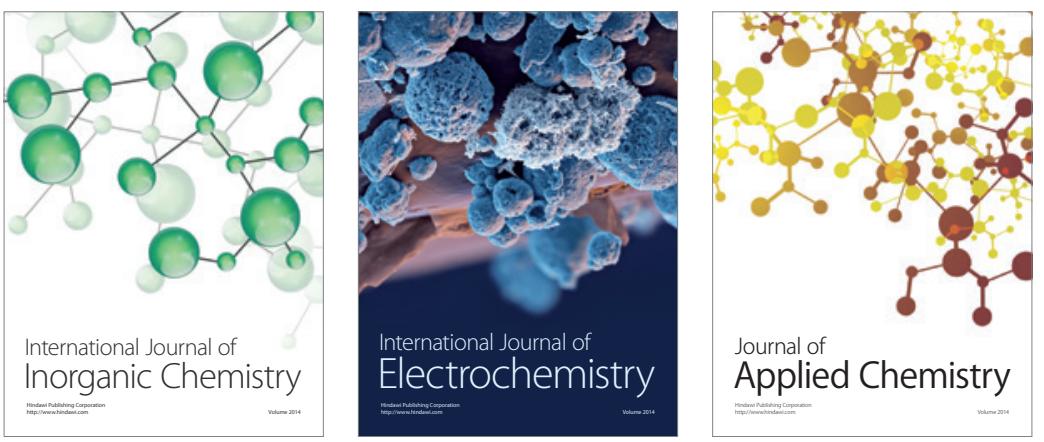

Journal of

Applied Chemistry
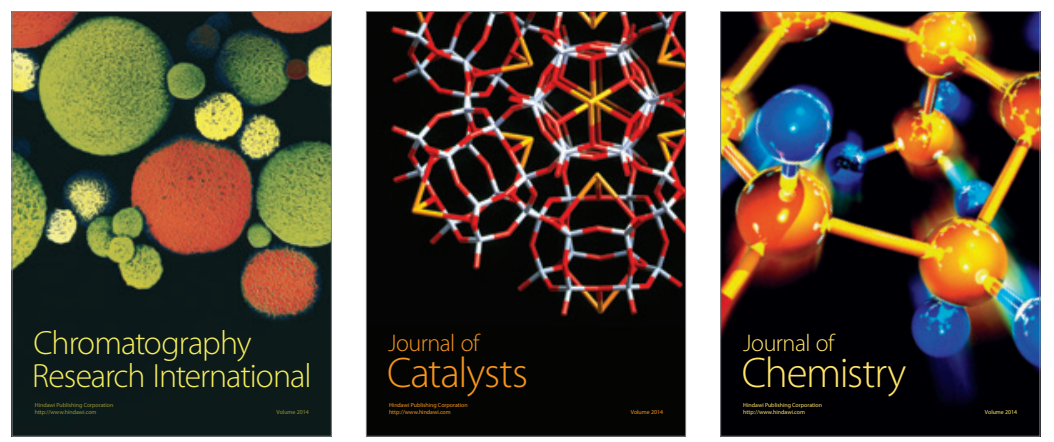
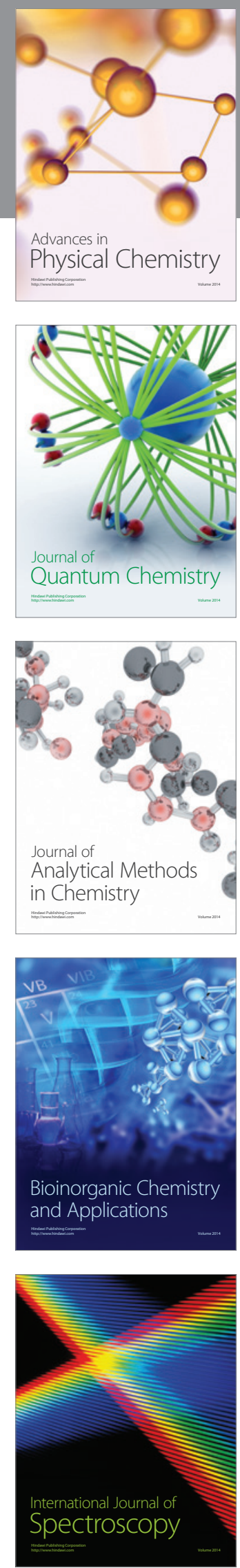